This is an electronic reprint of the original article. This reprint may differ from the original in pagination and typographic detail.

\author{
Author(s): Sipari, Saana; Haapakoski, Marko; Klemme, Ines; Palme, Rupert; Sundell, Janne; \\ Ylönen, Hannu
}

Title: $\quad$ Changing winter conditions in the boreal forest : the effects of fluctuating temperature and predation risk on activity and physiological stress level in bank voles

Year: $\quad 2016$

Version:

Please cite the original version:

Sipari, S., Haapakoski, M., Klemme, I., Palme, R., Sundell, J., \& Ylönen, H. (2016). Changing winter conditions in the boreal forest : the effects of fluctuating temperature and predation risk on activity and physiological stress level in bank voles. Behavioral Ecology and Sociobiology, 70(9), 1571-1579.

https://doi.org/10.1007/s00265-016-2165-4

All material supplied via JYX is protected by copyright and other intellectual property rights, and duplication or sale of all or part of any of the repository collections is not permitted, except that material may be duplicated by you for your research use or educational purposes in electronic or print form. You must obtain permission for any other use. Electronic or print copies may not be offered, whether for sale or otherwise to anyone who is not an authorised user. 


\title{
CHANGING WINTER CONDITIONS IN THE BOREAL FOREST: THE EFFECTS OF FLUCTUATING TEMPERATURE AND PREDATION RISK ON ACTIVITY AND STRESS IN BANK VOLES
}

\author{
Saana Sipari ${ }^{1}$, Marko Haapakoski ${ }^{1}$, Ines Klemme ${ }^{1}$, Rupert Palme ${ }^{3}$, Janne
} Sundell², and Hannu Ylönen ${ }^{1}$

1 Department of Biological and Environmental Science, Konnevesi Research Station, University of Jyväskylä, P.O.Box 35, FI-40014 Jyväskylä, Finland; 2 Lammi Biological Station, University of Helsinki, Pääjärventie 320, 16900 Lammi, Finland; 3 Institute of Physiology, Pathophysiology and Biophysics, Department of Biomedical Sciences, University of Veterinary Medicine, Vienna, Austria

\begin{abstract}
Due to the global climate change the winter conditions in the North are predicted to change, as the time with an intact snow cover gets shorter or disappears altogether. Many small ground dwelling animals, like rodents, are strongly dependent on protection provided by snow cover against cold and predators. Thus, lack of proper snow cover causing exposure to strong temperature fluctuations and increased predation risk could induce severe stress, causing alterations in the physical condition and behavior, and eventually lead to lower winter survival. To test this, we exposed bank voles (Myodes glareolus) to different temperature regimes and cues of predator threat under laboratory conditions. The test animals experienced either a stable but cool temperature regime resembling the stable conditions under snow cover, or an unstable diel temperature regime with cold nights and warmer days simulating the climate change scenario with unstable winter. After three weeks, the animals were additionally exposed to owl calls or sounds of non-predatory bird species. Stress levels, activity, food consumption and body mass were monitored. We observed that the voles exposed to unstable temperatures adjusted their normal mostly nocturnal circadian activity pattern towards a more diurnal rhythm without any significant responses in their stress level. Introducing the sound manipulation elevated the stress levels in females but not in males. However, the laboratory born voles were not able to distinguish between the sound of the non-predatory control bird and predatory bird and seemingly considered both as a threat. The sound induced stress levels did not differ between the temperature treatments. However, the temperature regime tended to affect anti-predator behavior as individuals experiencing unstable temperature and a threatening sound decreased their overall activity, unlike individuals under stable temperature treatments. Our results suggest that the ability of bank voles to plastically adjust their behavior may diminish the accumulation of stress when exposed to multiple stressors simultaneously.
\end{abstract}

Key words: climate change, winter, stress, unstable temperature, predation risk 


\section{INTRODUCTION}

The recent course of global climate change has raised many questions about its potential consequences on biodiversity and ecosystem functions around the world. Both local and global extinctions are predicted to occur due to the rapidly changing environmental conditions, as in many parts of the world the unpredictable events in climate (e.g. storms, drought) will be more pronounced than before (Lovejoy and Hannah 2005, Stocker et al. 2013). To persist in this kind of unstable environment is obviously demanding and requires plasticity from the organisms. The future course of many ecosystems in the northern parts of the world is of particular interest, as climate change is predicted to have notable consequences especially in these areas due to alterations in winter conditions (Moritz et al. 2002, Lovejoy and Hannah 2005, Stocker et al. 2013).

At high latitudes, snow cover during winter is characteristic and plays an important role in ecosystem dynamics, as many northern animals and plants are strongly dependent on the protection the snow provides against cold and predators (Marchand 1996, Stien et al. 2012, Wolkovich et al. 2012, Mills et al. 2013). However, due to global warming the winters in the North are about to go through some drastic changes as the time period with an intact snow cover gets shorter, or in the worst case, vanishes altogether (Serreze et al. 2000, Lovejoy and Hannah 2005, Jylhä et al. 2008). For small ground-dwelling mammals the lack of snow would expose them to severe temperature fluctuation and increase their susceptibility to many predators (Marchand 1996). This could lead to strongly elevated stress levels and consequently, deteriorated winter survival.

However, animals are capable of adapting to new environmental conditions but it often requires both behavioral and physiological responses to survive in suddenly deteriorating environmental circumstances (Wingfield and Sapolsky 2003, Boonstra 2004, Wingfield 2013, Boonstra et al. 2014). Under unfavorable external conditions animals usually face inevitable trade-offs. Often organisms allocate resources from acutely less vital functions, like reproduction or somatic growth (McNamara and Buchanan 2005, Bronson 2009). For example, under elevated predation pressure animals usually adjust their behavior accordingly, e.g. reducing activity and the time spent for foraging (Preisser et al. 2005). This, in the long run, however, can lead to an insufficient energy gain. In the case of abiotic stressors, such as cold stress, maintaining homeostasis by thermoregulation is energy consuming. If the availability and quality of nutrition is poor, it can eventually lead to the neglect of other physiological functions (e.g. immunocompetence) causing even pathological conditions (McEwen and Wingfield 2003, McEwen 2004, Beldomenico et al. 2008) When multiple stressful events occur simultaneously the reallocation of resources gets even more demanding (McNamara \& Buchanan 2005).

The unpredictable winter conditions and lack of a proper snow cover could expose small boreal mammals to several stressors at the same time. This could be the case especially during the early winter and early spring, as winters, in terms of permanent snow cover, are expected to become shorter in 
the future (Moritz et al. 2002, Lovejoy and Hannah 2005, Jylhä et al. 2008, Stocker et al. 2013). Here, we tested the hypothesis that climate change causes both behavioral and physiological responses in a boreal small mammal, the bank vole (Myodes glareolus). To mimic the possible effects of climate change we exposed test animals to different temperature regimes and cues of predators. Voles were experiencing either a stable but cool temperature regime resembling the stable conditions under the snow cover, or an unstable diel temperature regime with cold nights and warm days simulating the climate change scenario with unstable winter and early snow melt. In addition, we exposed animals to owl calls representing an elevated predation risk, or sounds of non-predatory bird species. Resident owls are a significant source of predation for small mammals and their activity includes frequent calling during late winter and early spring (Laine 2009, Korpimäki and Hakkarainen 2012). Our hypothesis was that under the climate change conditions without the protective snow cover the animals would be stressed because of the strong fluctuations in temperature and that they would adjust their activity towards a diurnal rhythm to avoid cold nights. We also predicted that unstable temperatures combined with predation threat would accumulate the stress reaction leading to strongly reduced overall activity. Thus, we expected to see the highest stress levels and the lowest activity in treatments with variable temperature and predatory cues. In stable temperature treatments with non-predatory bird sounds the activity was expected to stay species-typical and stress levels low (Eilam et al. 1999, Hettena et al. 2014).

\section{MATERIAL AND METHODS}

\section{Experimental animals}

All animals used in this study (40 males and 32 females) were born in the laboratory in April-July 2012 at the Konnevesi research station, Central Finland. To mimic the natural seasonal rhythm in the wild in Central Finland, voles were overwintered in climate chambers at $6{ }^{\circ} \mathrm{C}$ from November 2012 until the beginning of the experiment in April 2013. The light period was set to resemble the average light regime in winter time with 7 hours of light and 17 hours of darkness. As communal nesting is suggested to be common for Myodes voles during winter under natural conditions (Merritt 1984, Ylönen and Viitala 1985) we housed the voles in same-sex groups of four individuals in large cages $(60 \times 40 \times 20 \mathrm{~cm})$ until February. After that, they were separated in to individual standard mouse cages $(43 \times 26 \times 15 \mathrm{~cm})$ to habituate for the experiment. We also gradually increased the day length. All the voles had wood shavings and cotton wool as bedding and food (mice pellets, Labfor R36, Lantmännen) and water were provided ad libitum.

At the beginning of April 2013 all voles were weighed and injected with subcutaneous PIT tags for monitoring their activity (see below). After this, voles were introduced to their experimental cages (see below) and divided evenly into four climate chambers according to sex and body mass. In each 
chamber we housed 10 males and 8 females, and the mean body mass was approximately the same in all four treatments (mean $22.9 \pm 0.35 \mathrm{~g}, \mathrm{~F}_{1,68}=0.188$, $\mathrm{p}=0.666)$. Throughout the experiment the light regime of the chambers were set to $12 \mathrm{~L}: 12 \mathrm{D}$, resembling the day length of late winter/ early spring in Central Finland. The light regime was constant during the whole experiment.

\section{Experimental cages}

To monitor daily activity, standard mouse cages were equipped with a separating wall across the middle of the cage made from plywood and a hole large enough for a vole to go through $(\varnothing 5 \mathrm{~cm}$ ). In 36 (out of 74) of these cages there was a sensor (Trovan ${ }^{\circ}$, EID Aalten BV, Aalten, Holland) around the hole connected to a PC, which recorded each passage of the PIT-tagged individual through the hole (date and time) . The activity sensing cages were distributed equally across all treatments (18 for stable temperature chambers and 18 for unstable temperature chambers). The remaining cages had an otherwise similar structure but without the sensor system. Food and water were provided only in one side of the plywood wall, and nest material in the other.

\section{Experimental design}

The experiment was carried out in four temperature adjustable laboratories, i.e. climate chambers at the Konnevesi Research Station, Central Finland during April - May 2013. To study the effects of fluctuating temperature and predation risk on activity and stress levels in bank voles, we generated different treatments. Voles were experiencing either a stable but cool temperature mimicking the conditions under intact snow cover in late winter / early spring, or fluctuating daily temperature with cold nights and warm days representing the climate change scenario with unstable snow cover and early melting snow, exposing them to strong fluctuation of ambient temperature. In the stable temperature treatment the temperature was constant at $6^{\circ} \mathrm{C}\left(+/-1^{\circ} \mathrm{C}\right)$, whereas in the unstable temperature treatments it fluctuated from $1^{\circ} \mathrm{C}$ at night to $12^{\circ} \mathrm{C}$ during the day $\left(+/-1^{\circ} \mathrm{C}\right)$. Thus, the average daily temperature was approximately the same in both treatments. Under natural conditions the temperature would of course be lower, as the temperature under the snow cover stays generally around $0^{\circ} \mathrm{C}$, and the temperature fluctuations without the snow cover could be more severe. However, we want to emphasize, that the ultimate purpose of the manipulations was to act as an indicator of a stable environment and unstable environment, rather than examine the effect of absolute temperatures per se. Temperature manipulation continued through the whole experiment as described.

Predation risk was manipulated using tawny owl (Strix aluco) calls played from loudspeakers. Tawny owls are common nocturnal predators in forested areas, often occupying the same habitats as bank voles (Laine 2000). Songs of 
the redwing (Turdus iliacus), which is a non-predatory early arriving migrant thrush (Laine 2000), was used as a control. Depending on the treatment, either owl calls or thrush sounds were played three times per night (at 21:00, 01:00 and at 05:00) one hour at a time during two nights at standardized sound volume. However, to separate the possible reactions from stress caused by a new stimulus (i.e. new sound) and stress caused by recognized predation threat (owl calls), we performed a preceding sound treatment. One week before the actual predation manipulation, we exposed animals to a mixture of basic forest background sounds, e.g. distant birds, wind, water etc. Sounds of tawny owl (or any predatory species) or redwing were not present in the background recording. The sound regime was the same as above, but instead of two nights it was played for one week during each night.

With these manipulations we generated the following treatments: Unstable temperature with no sound treatment (UT/NS), unstable temperature /thrush song (UT/Control), unstable temperature / owl calls (UT/Owl). Also, stable temperature with no sound treatment (ST/NS), stable temperature / thrush song (ST/Control) and stable temperature / owl calls (ST/Owl). Temperature treatment remained the same for each individual through the whole experiment but sound manipulation alternated, so that each vole experienced both predator sound and control sound. To make the predator and control sound treatments more natural the owl calls and thrush song were recorded on top of slightly muffled background sound. The experiment was carried out according to following time table (Table 1).

Food consumption was measured by weighing the pellets given to the animals and weighing the leftovers. As an indicator of stress we used the level of corticosterone metabolites detected from the feces (Eccard et al 2011; Ylönen et al. 2006; Touma et al 2003; Sipari, Ylönen and Palme, unpublished results). The sound treatments (Owl or Control) were played during the first two nights of weeks 4 and 5. In the morning, after the second night, the pellet consumption was measured and fecal samples collected. The forest background sounds were always played during the rest of the week. Daily activity was monitored and recorded non-stop via the Trovan-system, but for activity analyses we selected $24 \mathrm{~h}$ periods from each week, the same for all individuals. At the end of the experiment all animals were weighed again.

\section{Fecal sampling and analysing}

To collect fecal samples each vole was temporarily moved to a clean and empty (no beddings) mouse cage. After the vole defecated it was returned to its home cage. This usually happened quickly, max. in one hour. After this, feces were collected to empty Eppendorf-tubes $(1.5 \mathrm{ml}$, one tube per individual per session) from the sampling cage using tweezers. Samples were stored at $-20{ }^{\circ} \mathrm{C}$. All fecal samples were analyzed by using $5 \alpha$-pregnane-3 $\beta, 11 \beta, 21$-triol-20-one enzyme immunoassay (EIA), with the methods described in Touma et al. 2003. This specific EIA has been validated and proven suitable for measuring fecal 
corticosterone metabolites in bank voles (Sipari, Ylönen and Palme, unpublished results). In that particular validation experiment it was shown that males excrete on average $70 \%$ of corticosterone metabolites via feces, whereas females excrete only around $50 \%$. Due to this significant difference we decided to adjust the measured corticosterone metabolite levels to the estimated value of $100 \%$ for both sexes for meaningful comparisons in our statistical analyses and in illustrations. All laboratory analyses were performed in the University of Veterinary Medicine, in Vienna, Austria.

\section{Statistical analyses}

Statistical analyses were performed using R 3.0.3 and IBM SPSS Statistics 20. Corticosterone metabolite levels (stress), activity, food consumption and body mass were all analysed using linear mixed model (with Gaussian error structure), fit by REML. Temperature treatment (ST and UT), sound treatment (NS, Control and Owl) and sex were set as fixed factors, and ID and chamber as random factors when analysing stress levels and activity. Stress levels were also tested between the sexes separately (see Material and methods, Fecal sampling and analysing). To compare night and day activity within and between groups during different sound treatments, the model was extended by adding time (12D:12L, night $=8 \mathrm{pm}-8 \mathrm{am}$ and day $=8 \mathrm{am}-8 \mathrm{pm}$ ) as a fixed factor. To control for playing order of Control and Owl sound we originally included the "order" as a fixed factor to our models. However, this caused strong multicollinearity between variables and we omitted this variable from the model. Instead, we tested the effect of playing order separately for stress levels and activity and found no significant effect. To test the effects of our treatments on body mass we used temperature treatment, time (start and end of the experiment) and sex as fixed factors, and ID and chamber as random factors. Food consumption was tested with temperature, sound treatment and sex as fixed factors, and again, ID and chamber as random factors. Daily food consumption was calculated by dividing the amount of food eaten by the number of days between measurements. For model selection we used the Akaike information criterion (AIC), model with the lowest AIC value selected for the analyses. To test for a correlation between stress level and total activity, and activity and food consumption, we used Spearman's correlation.

\section{RESULTS}

\section{Stress}

Stress levels measured as corticosteroid metabolites were significantly higher in males than in females $\left(\mathrm{F}_{1,64}=28.565, \mathrm{p}<0.001\right)$ throughout the experiment (Fig 1 ). When the sexes were analyzed separately, stress levels in females were significantly affected by the sound treatment $\left(\mathrm{F}_{2,53}=5.052, \mathrm{p}=0.010\right)$ but not by 
the temperature treatment $\left(\mathrm{F}_{1,30}=0.344, \mathrm{p}=0.562\right)$. In a pairwise comparison the stress levels in the Control were significantly higher than in NS $\left(\mathrm{T}_{55.37}=3.090, \mathrm{p}\right.$ $=0.009)$, and the difference between NS and Owl was nearly significant $\left(\mathrm{T}_{55.91}=\right.$ -2.384, $\mathrm{p}=0.052$ ). There was no significant difference between Control and Owl $\left(\mathrm{T}_{54.51}=0.674, \mathrm{p}=0.779\right)$. No significant interactions. In males there were no significant differences between any treatments (temperature: $F_{1,34}=0.398, p=$ 0.532 , sound: $\mathrm{F} 2,62=0.0278, \mathrm{p}=0.973)$. However, there was a significant interaction between temperature treatment and sound treatment $\left(\mathrm{F}_{2,62}=6.889\right.$, $p=0.002$ ), but in pairwise comparisons all differences were not significant (all comparisons $\mathrm{p}>0.080)$.

\section{Activity}

Total activity was significantly affected by the sound treatments $\left(\mathrm{F}_{2,119}=3.7749\right.$, $\mathrm{p}=0.026)$ but not by the temperature treatments $\left(\mathrm{F}_{1,28}=1.667, \mathrm{p}=0.207\right)$. The interaction of sound and temperature was close to significant $\left(\mathrm{F}_{2,119}=2.979, \mathrm{p}=\right.$ 0.055). Activity did not differ significantly between the sexes $\left(\mathrm{F}_{1,28}=0.902, \mathrm{p}=\right.$ 0.351). There were different trends in the response to the sound treatments between temperature groups (Fig 2). Individuals in ST treatment tended to increase their activity as a response to sound treatments, whereas individuals from UT decreased their activity. However, in the pairwise comparison only the difference in total activity between NS vs. Owl in UT group reached significance $(Z=3.436, p=0.008$, all other pairwise comparisons $>0.238)$. We observed no correlation between stress level and total activity $(\mathrm{r}=0.116, \mathrm{p}=$ $0.120)$. In general, individuals in ST treatment were significantly more active during night than day $(Z=-8.259, \mathrm{p}<0.001)$, whereas in UT treatment the difference was not significant $(Z=-1.671, p=0.339)$. The day time activity in ST treatment was significantly lower than in UT treatments $(Z=-3.136, p=0.009)$. No significant difference in night time activity between temperature treatments was observed $(Z=0.715, p=0.891)$. There were several significant interactions (temperature and time, sound and time, sex and time, and sound and sex; all p $<0.025)$.

\section{Body mass and food consumption}

Males were heavier than females throughout the experiment $\left(F_{1,67}=59.646, p\right.$ $<0.001)$. Also time had an effect on body mass, as the mean body mass was significantly lower at the beginning of the experiment than in the end $\left(\mathrm{F}_{1,56}=\right.$ $31.888 \mathrm{p}<0.001)$. There were no significant differences between temperature groups $\left(\mathrm{F}_{1,67}=0.067, \mathrm{p}=0.796\right)$, and no significant interactions.

Food consumption was significantly affected by the sound treatments $\left(\mathrm{F}_{2,126}=43.372, \mathrm{p}=0.001\right)$ but not by temperature treatments $\left(\mathrm{F}_{1,64}=1.232, \mathrm{p}=\right.$ 0.271). Food consumption was significantly lower in NS than Control and Owl (NS vs. Control: $Z=-7.613, p<0.001$, NS vs Owl $Z=-8.441, p<0.001$ ). There 
was no difference in food consumption between Control and Owl treatments $(\mathrm{Z}$ $=-0.823, p=0.689$ ). The increase in food consumption was, however, more likely time dependent rather than a consequence of the sound treatments. In a previous experiment conducted in the same climate chambers at the same time of the year (Sipari et al. 2014) an identical pattern in food consumption was observed without stressors other than temperature regimes. Males tended to eat more than females but the difference was not significant $\left(\mathrm{F}_{1,64}=3.834, \mathrm{p}=\right.$ $0.055)$. There was no correlation between activity and food consumption $(\mathrm{r}=$ $0.136, \mathrm{p}=0.218$ ).

\section{DISCUSSION}

Our results suggest that behavioral plasticity may diminish the accumulation of stress in bank voles when exposed to multiple stressors simultaneously. Voles in different temperature regimes did not show differences in stress levels, but individuals experiencing an unstable temperature regime with cold nights and warm days adjusted their activity towards a more diurnal rhythm compared to individuals under stable temperature, who remained species specifically more nocturnal. Both predator and control sound manipulations elevated stress levels in females, but in males no significant response was observed. We suggest that due to the laboratory origin, the voles used in the experiment did not distinguish the level of threat between the sound manipulations, but rather considered both of these sounds potentially threatening. However, we observed divergent trends in the behavioral response to the sound treatments under different temperature regimes. Voles exposed to unstable temperature conditions reduced their activity when encountering a threatening sound, whereas under stable temperature this reaction was not observed. Males had significantly higher stress levels than females throughout the experiment but the difference can be explained by their naturally higher basal level (Sipari, Palme and Ylönen, unpublished results).

Winter in boreal and polar regions is the most challenging season for most species. Thermoregulation is a physiological constraint and a stressor to animals experiencing temperatures far below their so called lower critical temperature (LCT). Lower critical temperature is the ambient temperature where an animal needs to adjust its behavior and physiological functions (e.g. increased/reduced mobility, energy intake, shivering) in order to maintain homeostasis (Marchand 1996). LCT is often season and acclimatization dependent (McDevitt and Speakman 1994, Marchand 1996). Exposure to cold increases the metabolic rate in non-hibernating small mammals (Wang et al. 1999, Cichon et al. 2002) and it decreases immunocompetence (Cichon et al.

2002). We hypothesized that compared to cool but stable temperature $\left(6^{\circ} \mathrm{C}\right)$, fluctuating cool temperatures $\left(1^{\circ} \mathrm{C}-12^{\circ} \mathrm{C}\right)$ could be even more challenging for small animals, due to the constant adjustment in thermoregulation it requires. However, we did not find significantly elevated stress levels in unstable temperature treatment, unlike expected. This result could indicate that voles 
acclimatized to cool temperature (see Material and methods) are relatively adaptable to changes in temperature, at least in the case of unrestricted food availability. Further, we observed a clear plasticity in their circadian activity patterns, which likely plays an important role in their successful adaptation to different temperature conditions. In bank voles the circadian rhythm in activity is polyphasic (Ylönen 1988, Halle 2000). Instead of one continuous phase of activity and rest bank voles have several activity bouts separated with resting periods during 24 hours periods. The majority of these activity bouts occur between dusk and dawn, while daytime activity is often relatively low (Ylönen 1988). However, as predicted, animals in unstable temperature treatments experiencing cold nights and warmer days increased their diurnal activity compared to individuals under stable temperature. Total activity did not differ between temperature treatments. Thus, our results suggest that bank voles are able to adjust their circadian activity patterns according to their environment, without any obvious stress reaction.

Introducing the sound treatments caused significantly elevated corticosterone metabolite levels in females but did not differ between the experienced temperature treatments. This implies, that due to the behavioral adjustments, e.g. shift in their circadian activity pattern, the fluctuating temperature combined with predation risk did not induce higher stress levels compared to the stable temperature treatments. The inability to recognize neutral sounds from predator sounds (also the thrush song caused significantly elevated corticosterone metabolite levels) may be explained by the laboratory origin of the voles. In males there were no significant differences in stress levels between any treatments. However, corticosterone levels as indicators of stress in males may be perhaps somewhat more complicated compared to females, as testosterone has been shown to strongly impact glucocorticoids and fear. It is generally accepted that stress reduces testosterone level (Chichinadze and Chichinadze 2008, Bronson 2009), but there is also strong evidence that animals with high testosterone level have lower stress hormone levels and are less fearful to novel stimuli (Cornwell-Jones and Kovanic 1981, Boissy and Bouissou 1994, Place and Kenagy 2000, Schradin 2008, Kohlhause et al. 2011). These results could explain some of the variance in stress levels between males in our experiment, especially in the unstable temperature treatments, as our previous experiment showed that variable spring temperature induces testosterone production in bank vole males (Sipari et al. 2014). In addition, despite the short day rhythm the animals experienced before the experiment, many of the individuals had external indications of sexual maturity already in February. This was unexpected and probably due to the laboratory origin of the voles. Also abundant food availability likely enhanced the maintenance of maturity.

Despite the lack of response on stress levels, the temperature treatments seemed to affect the behavioral response of bank voles when encountering a threatening sound. Voles exposed to unstable temperature conditions significantly reduced their activity in respond to the sound treatment, whereas voles under stable temperature rather increased their activity, though not 
significantly. This may indicate that abiotic environmental conditions may affect anti-predator behavior in bank voles. However, we should point out that the voles within a temperature group showed no statistically significant difference in activity when comparing their responses between the thrush sound and owl sound, only against treatment with no sound at all. That is why the term "anti-predator" behavior should be interpreted cautiously. Nevertheless, we consider using the term in this context justified, as based on our results it seems that both of these sounds were interpreted as a threat.

In prey animals, like voles, the anti-predator behavior is often divided in two main responses; fleeing and freezing. Based on the trend observed in our experiment it seems that the fleeing response was more pronounced under stable temperatures, whereas under unstable temperatures reduced activity was more common reaction. Anti-predator behavior can differ according to predator type (terrestrial or avian), distance to predator and behavior of the predator (immobile or approaching etc.) or whether the threat is direct or indirect (Ydenberg and Dill 1986, Eilam et al. 1999, Edut and Eilam 2004, Stankowich and Blumstein 2005, Blumstein 2006, Cooper et al. 2012). Also the geography of a habitat (open or covered) makes a difference (Jacob and Brown 2000). There are also indications that the reproductive stage and life history of an animal can affect anti-predator behavior (Borowski 2002, Brown and Shine 2004, Trebatická et al. 2010). Our results suggest that perhaps also the abiotic environmental conditions, such as climatic or weather conditions, could affect the chosen antipredator strategy. However, the reason for the different trends in the behavior between temperature treatments observed in our experiment is still unclear. Banks et al. 2002 showed that, due to the innate fear response, unfamiliar habitat increases immobility in Microtus voles. Perhaps one could argue that an unstable abiotic environment could act as some kind of unpredictability factor comparable to the unfamiliar habitat in the study of Banks et al. 2002.

Laboratory experiments often provide only a coarse indication and idea of the ecological interactions occurring under natural conditions. As anti-predator behavior is a summary of multiple factors, extrapolating our results to natural conditions as such is not possible. However, when speculating the feasibility of the observed responses, one could argue that the shift in the circadian activity pattern as well as reduced activity under predation risk observed in individuals in unstable temperature could be considered logical reaction under the conditions of the climate change scenario. Owls prey mainly based on their vision and hearing, thus, prey living in habitat with little shelter, e.g. no snow cover, would probably survive better by reducing activity. However, under long term predation risk the reduced activity could lead to energy deficiency if the food availability is scarce, as often is the case during winter. In our experiment there was no difference in food consumption nor body mass between temperature groups, despite the opposite activity trends between groups. This is probably due to the abundance and vicinity of the food source. Further, in the wild reduced mobility would eventually also increase the accumulation of scent cues (Banks et al. 2000), and likely increase the risk of 
mammalian scent-based predators. The shift in their circadian rhythm towards more diurnal activity is a logical response against nocturnal predators, as well as against cold nights, but could again increase the likelihood of being preyed on by day active predators. Nevertheless, these results provide an interesting aspect to the study of anti-predator behavior by suggesting that abiotic environmental factors might affect the anti-predator strategy in certain species.

\section{Conclusion}

Our results suggest that changes in winter conditions caused by the climate change may alter the circadian activity pattern and possibly even the antipredator behavior of bank voles. However, the adaptability and behavioral plasticity in bank voles may diminish the risk of pathological accumulation of stress effects in cases of multiple simultaneous stressors. On the other hand, not all stressors are equal. In addition to the suggested increase in winter time predation pressure and temperature related stress in small mammals, the food availability is suggested to become compromised. Thus, in future studies it would be interesting to test how the food limitation combined with different temperature or predation stressors would affect the behavioral and physiological responses, and potentially the winter survival in bank voles.

\section{REFERENCES}

Banks P.B., Norrdahl K. \& Korpimäki E. 2000. Nonlinearity in the predation risk of prey mobility. Proc. Biol. Sci. 267: 1621-1625.

Beldomenico P.M., Telfer S., Gebert S., Lukomski L., Bennett M. \& Begon M. 2008. Poor condition and infection: a vicious circle in natural populations. Proc. Biol. Sci. 275: 1753-1759.

Blumstein D.T. 2006. Developing an evolutionary ecology of fear: how life history and natural history traits affect disturbance tolerance in birds. Anim. Behav. 71: 389-399.

Boissy A. \& Bouissou M.F. 1994. Effects of androgen treatment on behavioral and physiological responses of heifers to fear-eliciting situations. Horm. Behav. 28: 66-83.

Boonstra R. 2004. Coping with changing northern environments: the role of the stress axis in birds and mammals. Integr. Comp. Biol. 44: 95-108.

Boonstra R., Dantzer B., Delehanty B., Fletcher Q.E. \& Sheriff M.J. 2014. Equipped for Life in the Boreal Forest: The Role of the Stress Axis in Mammals. Arctic 67: 82-97.

Borowski Z. 2002. Individual and seasonal differences in antipredatory behaviour of root voles a field experiment. Can. J. Zool. 80: 1520-1525.

Bronson F.H. 2009. Climate change and seasonal reproduction in mammals. Philos. Trans. R. Soc. Lond. B. Biol. Sci. 364: 3331-3340. 
Brown G. \& Shine R. 2004. Effects of reproduction on the antipredator tactics of snakes (Tropidonophis mairii, Colubridae). Behav. Ecol. Sociobiol. 56: 257262.

Chichinadze K. \& Chichinadze N. 2008. Stress-induced increase of testosterone: Contributions of social status and sympathetic reactivity. Physiol. Behav. 94: 595-603.

Cichon M., Chadzinska M., Ksiazek A. \& Konarzewski M. 2002. Delayed effects of cold stress on immune response in laboratory mice. Proc. Biol. Sci. 269: 1493-1497.

Cooper W.E., López P., Martín J. \& Pérez-Mellado V. 2012. Latency to flee from an immobile predator: effects of predation risk and cost of immobility for the prey. Behav. Ecol. 23: 790-797.

Cornwell-Jones C.A. \& Kovanic K. 1981. Testosterone reduces olfactory neophobia in male golden hamsters. Physiol. Behav. 26: 973-977.

Eccard J.A., Fey K., Caspers B.A. \& Ylonen H. 2011. Breeding state and season affect interspecific interaction types: indirect resource competition and direct interference. Oecologia 167: 1-11.

Edut S. \& Eilam D. 2004. Protean behavior under barn-owl attack: voles alternate between freezing and fleeing and spiny mice flee in alternating patterns. Behav. Brain. Res. 155: 207-216.

Eilam D., Dayan T., Ben-Eliyahu S., Schulman I., Shefer G. \& Hendrie C.A. 1999. Differential behavioural and hormonal responses of voles and spiny mice to owl calls. Anim. Behav. 58: 1085-1093.

Halle S. 2000. Voles-small graminivores with polyphasic patterns. In: Anonymous Activity patterns in small mammals, Springer, pp. 191-215.

Hettena A.M., Munoz N. \& Blumstein D.T. 2014. Prey Responses to Predator's Sounds: A Review and Empirical Study. Ethology 120: 427-452.

Jacob J. \& Brown J.S. 2000. Microhabitat use, giving-up densities and temporal activity as short- and long-term anti-predator behaviors in common voles. Oikos 91: 131-138.

Jylhä K., Fronzek S., Tuomenvirta H., Carter T.R. \& Ruosteenoja K. 2008. Changes in frost, snow and Baltic sea ice by the end of the twenty-first century based on climate model projections for Europe. Clim. Change 86: 441-462.

Kohlhause S., Hoffmann K., Schlumbohm C., Fuchs E. \& Flügge G. 2011. Nocturnal hyperthermia induced by social stress in male tree shrews: relation to low testosterone and effects of age. Physiol. Behav. 104: 786-795.

Korpimäki E. \& Hakkarainen H. 2012. The Boreal Owl: ecology, behaviour and conservation of a forest-dwelling predator. Cambridge University Press.

Laine L.J. 2009. Suomen luonto-opas. WSOY.

Lovejoy T.E. \& Hannah L.J. 2005. Climate change and biodiversity / edited by Thomas E. Lovejoy \& Lee Hannah. Yale University Press.

Marchand P.J. 1996. Life in the cold: an introduction to winter ecology. University Press of New England. 
McDevitt R.M. \& Speakman J.R. 1994. Limits to sustainable metabolic rate during transient exposure to low temperatures in short-tailed field voles (Microtus agrestis). Physiol. Zool. 67: 1103-1116.

McEwen B.S. 2004. Protection and damage from acute and chronic stress: allostasis and allostatic overload and relevance to the pathophysiology of psychiatric disorders. Ann. N. Y. Acad. Sci. 1032: 1-7.

McEwen B.S. \& Wingfield J.C. 2003. The concept of allostasis in biology and biomedicine. Horm. Behav. 43: 2-15.

McNamara J. \& Buchanan K. 2005. Stress, resource allocation, and mortality. Behav. Ecol. 16: 1008-1017.

Merritt J.F. 1984. Winter ecology of small mammals. Carnegie Museum of Natural History, Pittsburgh.

Mills L.S., Zimova M., Oyler J., Running S., Abatzoglou J.T. \& Lukacs P.M. 2013. Camouflage mismatch in seasonal coat color due to decreased snow duration. Proc. Natl. Acad. Sci. U S A 110: 7360-7365.

Moritz R.E., Bitz C.M. \& Steig E.J. 2002. Dynamics of recent climate change in the Arctic. Science 297: 1497-1502.

Place N. \& Kenagy G. 2000. Seasonal changes in plasma testosterone and glucocorticosteroids in free-living male yellow-pine chipmunks and the response to capture and handling. J. Comp. Physiol. B. 170: 245-251.

Preisser E.L., Bolnick D.I. \& Benard M.F. 2005. Scared to death? The effects of intimidation and consumption in predator-prey interactions. Ecology 86: 501-509.

Schradin C. 2008. Seasonal changes in testosterone and corticosterone levels in four social classes of a desert dwelling sociable rodent. Horm. Behav. 53: 573-579.

Serreze M., Walsh J., Chapin Iii F., Osterkamp T., Dyurgerov M., Romanovsky V., Oechel W., Morison J., Zhang T. \& Barry R. 2000. Observational evidence of recent change in the northern high-latitude environment. Clim. Change 46: 159-207.

Sipari S., Haapakoski M., Klemme I., Sundell J. \& Ylönen H. 2014. Sex-specific variation in the onset of reproduction and reproductive trade-offs in a boreal small mammal. Ecology 95: 2851-2859.

Stankowich T. \& Blumstein D.T. 2005. Fear in animals: a meta-analysis and review of risk assessment. Proc. Biol. Sci. 272: 2627-2634.

Stien A., Ims R.A., Albon S.D., Fuglei E., Irvine R.J., Ropstad E., Halvorsen O., Langvatn R., Loe L.E., Veiberg V. \& Yoccoz N.G. 2012. Congruent responses to weather variability in high arctic herbivores. Biology letters 8: 1002-1005.

Stocker T.F., Qin D., Plattner G., Tignor M., Allen S.K., Boschung J., Nauels A., Xia Y., Bex V. \& Midgley P.M. 2013. Climate change 2013: The physical science basis. Intergovernmental Panel on Climate Change, Working Group I Contribution to the IPCC Fifth Assessment Report (AR5)(Cambridge Univ Press, New York). 
Touma C., Sachser N., Möstl E. \& Palme R. 2003. Effects of sex and time of day on metabolism and excretion of corticosterone in urine and feces of mice. Gen. Comp. Endocrinol. 130: 267-278.

Trebatická L., Ketola T., Haapakoski M., Opperbeck A. \& Ylönen H. 2010. Is Fear a Factor in Voles? Short Term Physiological and Behavioural Response to Predation Stress. Open Ecology Journal 3: 16-21.

Wang D., Sun R., Wang Z. \& Liu J. 1999. Effects of temperature and photoperiod on thermogenesis in plateau pikas (Ochotona curzoniae) and root voles (Microtus oeconomus). J. Comp. Physiol. B. 169: 77-83.

Wingfield J. \& Sapolsky R. 2003. Reproduction and resistance to stress: when and how. J. Neuroendocrinol. 15: 711-724.

Wingfield J.C. 2013. The comparative biology of environmental stress: behavioural endocrinology and variation in ability to cope with novel, changing environments. Anim. Behav. 85: 1127-1133.

Wolkovich E.M., Cook B.I., Allen J.M., Crimmins T.M., Betancourt J.L., Travers S.E., Pau S., Regetz J., Davies T.J., Kraft N.J.B., Ault T.R., Bolmgren K., Mazer S.J., McCabe G.J., McGill B.J., Parmesan C., Salamin N., Schwartz M.D. \& Cleland E.E. 2012. Warming experiments underpredict plant phenological responses to climate change. Nature 485: 494-7.

Ydenberg R.C. \& Dill L.M. 1986. The economics of fleeing from predators. Adv. Study Behav. 16: 229-249.

Ylönen H. 1988. Diel activity and demography in an enclosed population of the vole Clethrionomys glareolus(Schreb.). Ann. Zool. Fennici 25: 221-228.

Ylönen H. \& Viitala J. 1985. Social organization of an enclosed winter population of the bank vole Clethrionomys glareolus. Ann. Zool. Fennici 22: 353-358.

Ylönen H., Eccard J.A., Jokinen I. \& Sundell J. 2006. Is the antipredatory response in behaviour reflected in stress measured in faecal corticosteroids in a small rodent? Behav. Ecol. Sociobiol. 60: 350-358. 
TABLE 1. The time table of the experiment

\begin{tabular}{|c|l|r|}
\hline Time & \multicolumn{1}{|c|}{ Treatment } & \multicolumn{1}{|c|}{ Experimental procedures } \\
\hline Week 1 & Temperature (ST, UT), no sound & - no procedures, habituation \\
& & period \\
\hline Week 2 & Temperature (ST, UT), no sound & - monitoring daily activity \\
& & - measuring food consumption \\
& & - collecting fecal samples \\
\hline Week 3 & Temperature + Back ground sound & nound \\
\hline Week 4 & Temperature + Owl or Control sound & - monitoring daily activity \\
& & - measuring food consumption \\
& & - collecting fecal samples \\
\hline Week 5 & Temperature + Owl or Control sound & - monitoring daily activity \\
& (reversed) & - collecting fecal samples \\
& & \\
\hline
\end{tabular}

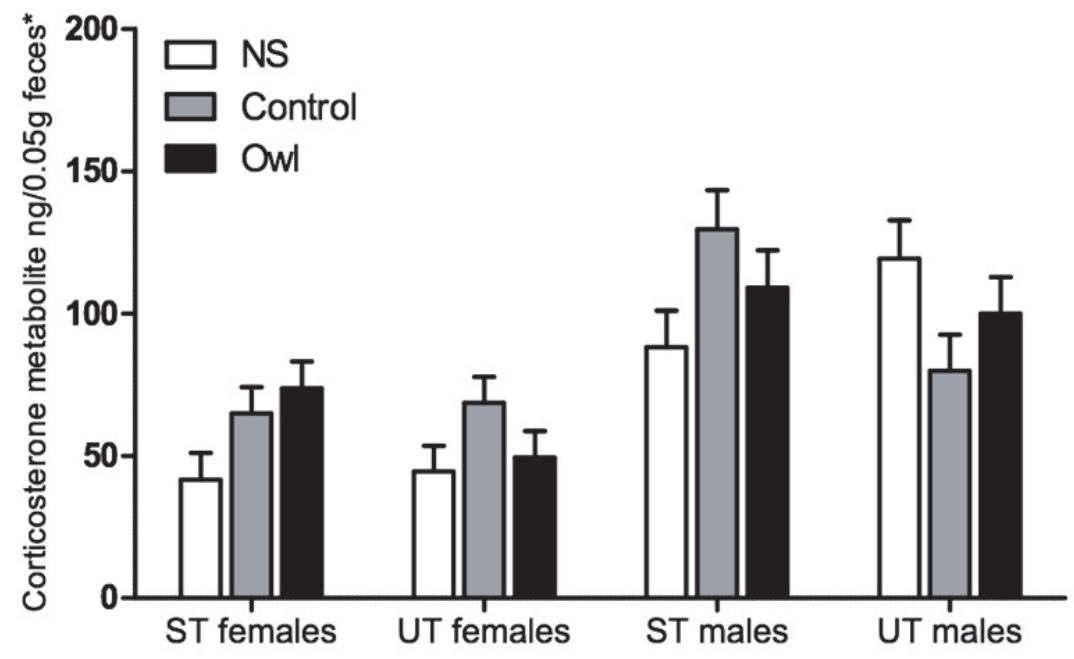

Treatments

FIGURE 1 LS-means (with SE) of corticosterone metabolite levels indicating stress in different treatments for females and males. ST $=$ stable temperature treatment, $\mathrm{UT}=$ unstable temperature treatment. NS $=$ no sound, Control $=$ control sound and Owl $=$ predator sound $\left({ }^{*}\right.$ To enable accurate comparison between sexes the metabolite levels are adjusted. See Material and methods). 


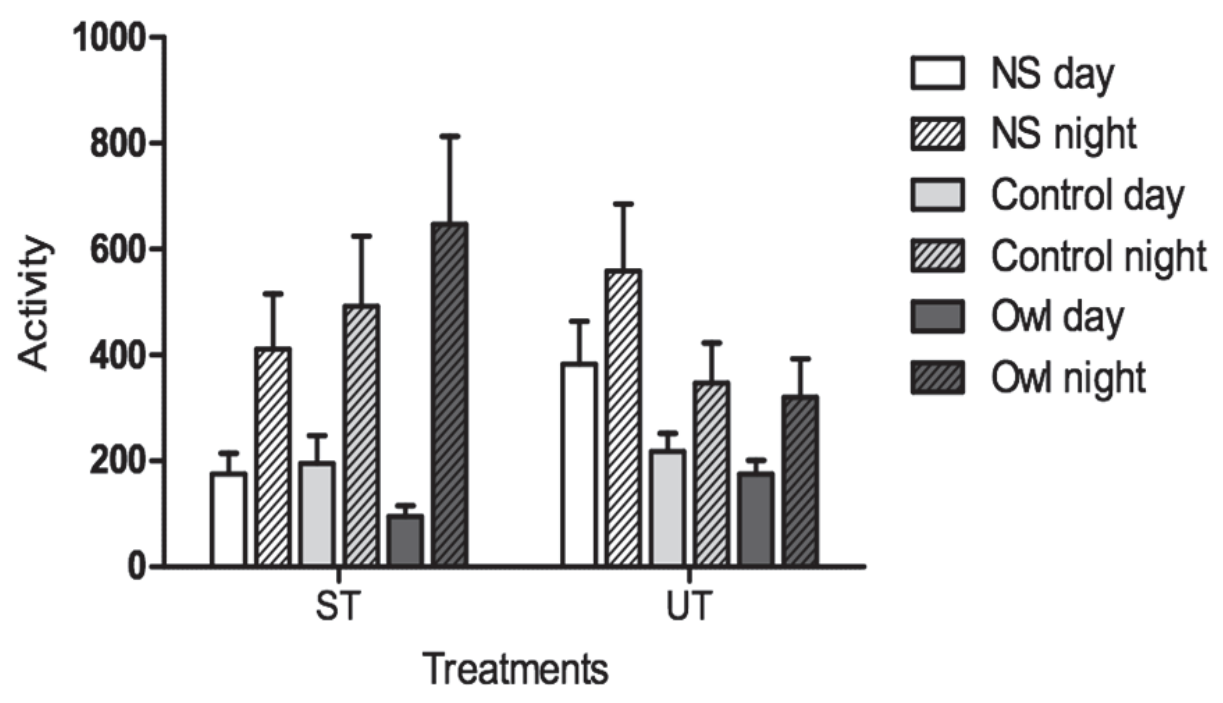

FIGURE 2 LS-mean (with SE) activity during day and night in different treatments. Activity on $\mathrm{x}$-axis represents the frequency of recorded entries through the sensor hole in the experimental cages during 24 hours (see Material and methods, Experimental cages). ST = stable temperature treatment, UT = unstable temperature treatment, NS = no sound, Control $=$ control sound and Owl $=$ predator sound . 